\title{
A dipeptidyl peptidase inhibitor, evogliptin, directly prevents nephrin loss and podocyte damage via post- transcriptional regulation
}

\author{
Cheong YH, Park H, Jung IH, Chae YN, Kim TH, Lee BR and Kim MK* \\ Dong-A Socio Research Center, Dong-A ST Co., Ltd., Yongin, 17073, Republic of Korea
}

\begin{abstract}
Background: Loss of podocytes due to podocyte damage leads to impairment of renal filtration function, thereby bringing about proteinuria in glomerular diseases. Dipeptidyl peptidase 4 (DPP4) inhibitors are reported to protect against podocyte damage in preclinical animal models. However, the direct effects of DPP4 inhibitors on podocytes are not yet fully understood.

Methods: Streptozotocin-induced diabetic mice and db/db mice were provided with evogliptin, linagliptin, or irbesartan for 12 weeks. Mouse and human podocytes were treated for $72 \mathrm{~h}$ and cell lysate and medium were analyzed.

Results: In diabetic mice with renal impairment, evogliptin treatment was more efficacious than linagliptin in blocking urinary nephrin excretion, with preserved renal nephrin and phospho-nephrin levels observed regardless of glucose control. In differentiated murine podocytes and primary human podocytes, evogliptin also outperformed linagliptin in preserving nephrin protein levels under high glucose and angiotensin II conditions that mimicked diabetic nephropathy conditions. Intriguingly, after $72 \mathrm{~h}$ of treatment, evogliptin effectively blocked the increase in cellular DPP4 activity without altering DPP4 expression levels, while linagliptin did not. Blocking protein synthesis or clathrin-mediated endocytosis eliminated the nephrin-preserving effects of evogliptin, but nephrin gene expression was not altered by any treatments, suggesting potential post-transcriptional regulation. In podocytes, evogliptin directly reduced the stress-induced cellular signals, pro-apoptotic protein cleavage and shedding of membrane DPP4 that increased under diabetic nephropathy-mimicking conditions.
\end{abstract}

Conclusions: Our findings suggest a direct protective effect of evogliptin against podocyte damage through maintenance of nephrin levels, alleviation of stress responses and a reduction in apoptotic cell death.

\begin{abstract}
Abbreviations: ACTB: beta actin; ANOVA: analysis of variance; ARB: angiotensin receptor blocker; CKD: chronic kidney disease; DN: diabetic nephropathy; DPP4: dipeptidyl peptidase 4; ELISA: enzymelinked immunosorbent assay; GLP-1: glucagon-like peptide-1; HRP: horseradish peroxidase; ICAM: intercellular adhesion molecules; MMP: matrix metalloprotease; MAP: mitogen-activated protein; M6P/ IGFIIR: mannose 6-phosphate/insulin-like growth factor II receptor; NPHS1: nephrin; NF-kB: nuclear factor kappa-light-chain-enhancer of activated B cells; PAI: plasminogen activator inhibitor; PAR2: proteaseactivated receptor 2; PARP: poly ADP ribose polymerase; PAS: periodic acid-schiff; PBS: phosphate-buffered saline; PDXX11: podocalyxin; RAS: renin-angiotensin system; SDF-1: stromal cell-derived factor-1; STZ: streptozotocin; TGF $\beta$ : tumor growth factor $\beta$; TNF: tumor necrosis factor; WT-1: Wilms tumor protein; VEGFA: vascular endothelial growth factor-A.
\end{abstract}

\section{Introduction}

\section{Background}

Chronic kidney disease (CKD) affects over $10 \%$ of the population worldwide and is an independent risk factor for adverse cardiovascular outcomes [1]. Type 2 diabetes is the most common cause of CKD, and in the United States, $>40 \%$ of diabetic patients have diabetic nephropathy (DN), which is the main complication of type 2 diabetes and leads to thickening of the glomerular basement membrane, glomerular hypertrophy, mesangial expansion, and overt renal disease [2]. Persistent albuminuria is a hallmark of $\mathrm{DN}$, which commonly arises from damage of glomerular podocytes. Podocytes compose slit diaphragms that function as the final barrier against flow of macromolecules into the urine [3]. It has been suggested that the initial stages of the loss of the permeability barrier in DN are associated with nephrin [4]. Nephrin, a $180 \mathrm{kDa}$, trans-membrane protein in podocytes, was the first molecule identified in the slit between podocyte foot processes and is a major component of the slit diaphragm [5]. Therefore, in addition to podocyte loss, reduced nephrin levels may also lead to development of proteinuria.

Over the past decade, dipeptidyl peptidase 4 (DPP4) inhibitors have been used in the clinic for glucose control in patients with type 2 diabetes because they stimulate pancreatic insulin secretion by enhancing the biological half-life of glucagon-like peitide-1 (GLP-

${ }^{\star}$ Correspondence to: Mi-Kyung Kim, Ph.D, Department of Discovery Biology, Dong-A Socio Research Center, 21, Geumhwa-ro 105beon-gil, Giheung-gu, Yongin-si, Gyeonggi-do, 17073, Republic of Korea, Tel: +82-31-280-1362, E-mail: kmk8544@gmail.com

Key words: dipeptidyl peptidase 4 (DPP4), evogliptin, nephrin, podocyte

Received: December 11, 2019; Accepted: December 30, 2019; Published: January 06, 2020 
1), one of endogenous substrates of DPP4 enzyme [6]. Meanwhile, DPP4 inhibitors have shown to alleviate albuminuria in diabetic patients with renal dysfunction $[7,8]$. DPP4 inhibitors also have shown renoprotective effects in animals with renal dysfunction caused by diverse pathophysiological processes, including DN. The underlying mechanisms have been reported to be associated with hypoglycemic effects and reduction of oxidative stress, inflammation, apoptosis, fibrosis and endothelial-mesenchymal transition [9-11]. On the other hand, among the currently available DPP4 inhibitors, only a few have been reported to inhibit podocyte injury in vivo and thereby attenuate proteinuria [12-14]. Moreover, to date, there is a paucity of information on how DPP4 inhibitors act directly on podocytes apart from their GLP-1-dependent systemic effects [14,15].

DPP4 expression is higher in podocytes than in mesangial cells [15]. Membrane-bound DPP4 localizes preferentially to the membrane of the podocyte foot process and slit diaphragm [12]. Thus, we postulate that DPP4 may play a crucial role in regulation of podocytes. Herein, we explore and compare the direct effects of DPP4 inhibitors on podocytes.

\section{Methods and materials}

Evogliptin L-tartrate salt and irbesartan were synthesized inhouse at Dong-A Socio Research Center (Figure 1). Linagliptin was purchased from Letopharm Ltd. (Shanghai, China). Unless otherwise specified, chemicals and cell culture reagents were obtained from Sigma-Aldrich (St. Louis, USA) and Life Technologies (San Francisco, USA), respectively.

\section{Ethics statement}

All experiments were performed in compliance with Korean legislation under the Laboratory Animal Act 2009 and were approved by the Institutional Animal Care and Use Committee of Dong-A ST Co., Ltd. Mice were maintained at $23 \pm 2^{\circ} \mathrm{C}$ on a 12:12-h light-dark cycle (lights on 0700-1900 h). Mice received a standard diet (10 kcal\% fat diet, Purina \#38057, Cargill Agri Purina, Seoul, Korea) with free access to food and water. A sample size of eight mice per group was used based on prior studies $[14,16]$.

\section{Animal studies}

Seven-week-old male C57BL/6 mice were purchased from JungAng Lab Animal Inc. (Seoul, South Korea). After 1-week of acclimation, streptozotocin (STZ; $65 \mathrm{mg} / \mathrm{kg}$ ) was intraperitoneally injected for 5 consecutive days. Six days after the last injection, STZ mice with blood glucose levels $\geq 250 \mathrm{mg} / \mathrm{dl}$ for two consecutive days were selected and randomized into 4 groups based on body weight and blood glucose levels. The doses of irbesartan and linagliptin were chosen based on the highest dose applied to the original indications in mice [17,18]. For 12 weeks, mice received a standard diet mixed with or without each drug as follows: Normal control, STZ control, irbesartan $(0.021 \%(\mathrm{w} / \mathrm{w})$ for 50 $\mathrm{mg} / \mathrm{kg} /$ day), linagliptin $(0.004 \%$ (w/w) for $10 \mathrm{mg} / \mathrm{kg} /$ day $)$, or evogliptin $(0.042 \%(\mathrm{w} / \mathrm{w})$ for $100 \mathrm{mg} / \mathrm{kg} /$ day $)$. At the end of the experiment, the mean administered doses were computed to be $58.1 \pm 7.0,10.4 \pm 0.4$, and $117.3 \pm 2.6 \mathrm{mg} / \mathrm{kg} /$ day, respectively.

Five-week-old male C57BLKS/J-db/db (db/db) mice and C57BL/6 mice were purchased from Jung-Ang Lab Animal Inc. (Seoul, South Korea). After 2 weeks of acclimation, db/db mice were assigned to 5 groups according to body weight, blood glucose, and urine volume. To reduce the stress caused by animal handling, drugs were given to mice as a drug-diet admixture for 12 weeks as follows: irbesartan $(0.033 \%$ (w/w) for $50 \mathrm{mg} / \mathrm{kg} /$ day) [19], linagliptin $(0.002 \%(\mathrm{w} / \mathrm{w})$ for 3 $\mathrm{mg} / \mathrm{kg} /$ day) [12], evogliptin-L (0.067\% (w/w) for $100 \mathrm{mg} / \mathrm{kg} /$ day $)$, and

A<smiles>CC(C)(C)OCC1C(=O)NCCN1C(=O)CC(N)Cc1cc(F)c(F)cc1F</smiles>

Evogliptin

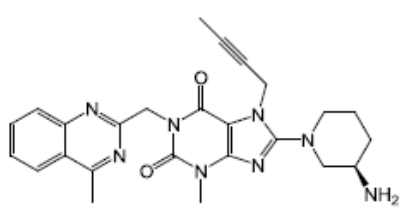

Linagliptin

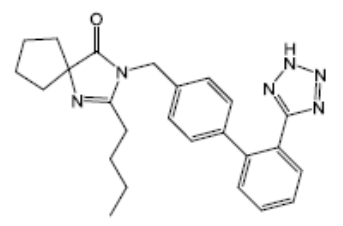

Irbesartan

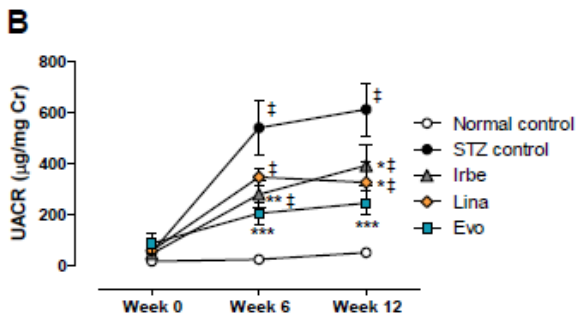

C

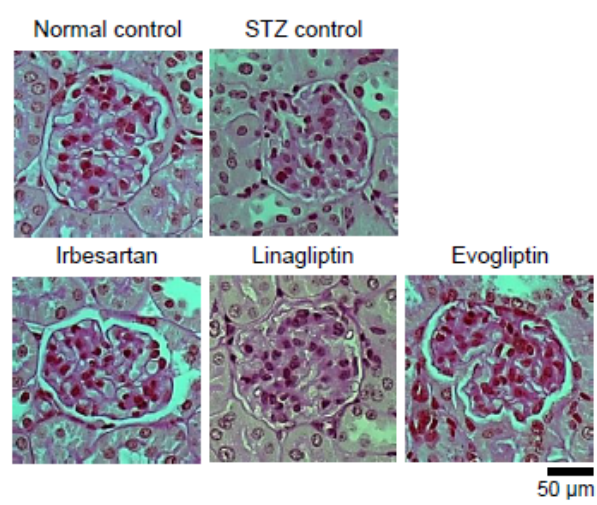

Figure 1. Comparison of renoprotective effects in streptozotocin (STZ)-induced diabetic mice. Chemical structures of evogliptin, linagliptin and irbesartan (A). STZ-induced diabetic mice were provided with drug-diet admixtures for 12 weeks. The data denote changes in the urinary albumin-creatinine ratio (UACR) during the 12-week treatment with each drug; the target dose was $50 \mathrm{mg} / \mathrm{kg} / \mathrm{day}, 10 \mathrm{mg} / \mathrm{kg} /$ day, and $100 \mathrm{mg} / \mathrm{kg} /$ day for irbesartan, linagliptin, and evogliptin, respectively (B). Representative photographs of PAS-stained renal tissue (original magnification $\mathrm{x} 200$ ). ${ }^{\star}, \mathrm{p}<0.05$ vs normal control; *, **, and ***, $<<0.05, \mathrm{p}<0.01$, and $\mathrm{p}<0.001$, respectively, vs STZ control at each time point (determined by RM two-way ANOVA) 
evogliptin-H (0.2\% for $300 \mathrm{mg} / \mathrm{kg} /$ day) [20]. The mean administered doses were calculated to be $55.3 \pm 4.9,2.6 \pm 0.3,87.1 \pm 9.3$, and $232.1 \pm 28.8 \mathrm{mg} / \mathrm{kg} /$ day for irbesartan, linagliptin, evogliptin-L and evogliptin- $\mathrm{H}$, respectively.

Body weight and fed blood glucose levels were monitored biweekly. Daily food intake, water intake, and urine volume were measured every 6 weeks. At the end of the experiment, mice were euthanized without fasting. Then, kidney tissue and plasma samples were collected for histological and biochemical analyses. Plasma glucose and urine creatinine levels were measured with an enzymatic method using a Konelab 20i analyzer (Waltham, USA). Urinary albumin and nephrin levels were determined with a mouse albumin enzyme-linked immunosorbent assay (ELISA) kit (ALPCO, New York, USA) and a mouse nephrin ELISA kit (Exocell, Philadelphia, USA), respectively.

\section{Podocyte cell line}

A thermosensitive SV-40-transfected immortalized mouse podocyte cell line (up to 20 passages) was kindly provided by Prof. Dae Ryong Cha at Korea University Ansan Hospital, Ansan, Korea. For differentiation, mouse podocytes were cultivated on plates coated with type 1 collagen containing RPMI1640 medium supplemented with $10 \%$ fetal bovine serum at $37^{\circ} \mathrm{C}$ for 14 days. Primary human podocytes (\#36036-08; up to 12 passages) were obtained from Celprogen Inc. (San Pedro, USA) and maintained in precoated culture ware (\#E36036-08) containing a complete growth medium (\#M36036-08S) supplemented with $10 \%$ fetal bovine serum, 100 units $/ \mathrm{ml}$ penicillin $\mathrm{G}$ and $100 \mu \mathrm{g} / \mathrm{ml}$ streptomycin at $37^{\circ} \mathrm{C}$ in a humidified incubator with $5 \% \mathrm{CO}_{2}$ [21]. To mimic DN conditions, cells were treated with $30 \mathrm{mM}$ D-glucose and $100 \mathrm{nM}$ angiotensin II in the presence or absence of each drug for $72 \mathrm{~h}$.

\section{Histology and immunohistochemistry}

For determining mesangial expansion, $4-\mu \mathrm{m}$ thick slices of kidney were stained with a Periodic Acid-Schiff (PAS) Stain kit (\# 395B, Sigma-Aldrich, St. Louis, USA) followed by counterstaining with hematoxylin according to the manufacturer's instructions. For immunohistochemical staining, the sections were stained with rabbit anti-synaptopodin (1:200; SC-50459, Santa Cruz Biotechnology, Santa Cruz, USA) or with guinea pig anti-nephrin (1:50; PROGEN Biotechnik, Heidelberg, Germany) antibody at $4^{\circ} \mathrm{C}$ overnight. Then, the sections were stained with horseradish peroxidase-conjugated secondary antibody at room temperature for $2 \mathrm{~h}$. Immunoreactive areas were detected using 3,3'-diaminobenzidine tetrahydrochloride (DAB, Millipore, Bedford, USA) followed by counterstaining with hematoxylin. Digital images were captured using an Axioskop 2 plus microscope (Carl Zeiss, Oberkochen, Germany).

\section{Immunoblotting}

Each sample (30-100 $\mu$ g protein) was separated on $4-12 \%$ BisTris gradient gels (Life Technologies, Carlsbad, USA), transferred to a membrane, and then treated with the following primary antibodies at $4^{\circ} \mathrm{C}$ overnight: goat anti-nephrin (Nphs1) (1:200, \#SC-19000, Santa Cruz Biotechnology, Dallas, USA), rabbit anti-nephrin (1:1,000, \#169878, USBiological Life Science, Swampscott, USA), rabbit antiphospho-nephrin (Y1217 for human or Y1232 for mouse) (1:200, \#ab80298, Abcam, Cambridge, USA), rabbit anti-DPP4 (1:1,000, \# LSB11802, LSBio, Seattle, USA), goat anti-mouse podocalyxin (Podxl1) (1:1,000, \#AF1556, R\&D Systems, Minneapolis, USA), mouse antiWilms Tumor Protein (Wt1) (1:1,000, \#ab201948, Abcam), rabbit antivascular endothelial growth factor-A (Vegfa) (1:1,000, \#PAB12284,
Abnova, Taipei, Taiwan), rabbit anti- poly ADP ribose polymerase (PARP) (1:1,000, \#9542, Cell Signaling Technology, Beverly, USA), rabbit anti-cleaved caspase-3 (1:1,000, \#9664, Cell signaling Technology), and rabbit anti- $\beta$-Actin (Actb) $(1: 5,000$, \#4967L, Cell Signaling Technology). Then, secondary antibodies were incubated as follows: horse radish peroxidase (HRP)-conjugated rabbit anti-goat $\operatorname{IgG}\left(1: 5,000, \# 31402\right.$, ThermoFisher scientific) $4^{\circ} \mathrm{C}$ overnight, HRPconjugated goat anti-rabbit IgG $(1: 5,000, \# 7074$ S, Cell Signaling) and goat anti-mouse IgG (1:2,000,\#62-6520, ThermoFisher Scientific) at room temperature for $1 \mathrm{~h}$. Immunospecific proteins were visualized by adding Chemiluminescent FemtoMax ${ }^{\mathrm{Tm}}$ Super Sensitive HRP Substrate (Rockland, Hamburg, Germany), and digital images were captured using a Bio-Rad ChemiDocTMXRS+ system (Bio-Rad, Hercules, USA).

\section{Real-time quantitative polymerase chain reaction (qPCR)}

Target gene expression was quantified via SYBR Green qRT-PCR using a LightCycler 480 II System (Roche Applied Science, Indianapolis, USA). $18 \mathrm{~S}$ ribosomal RNA levels were determined with the TaqMan ${ }^{\circ}$ probe method or SYBR Green method. Information regarding primers and probes used is listed in Table 1. Relative gene expression was normalized to $18 \mathrm{~S}$ ribosomal RNA $(\Delta \mathrm{Ct})$, and treatment effects were

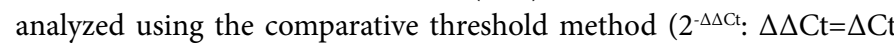
(treatment) - $\Delta \mathrm{Ct}$ (untreated control)).

\section{DPP4 activity assay}

DPP4 enzyme activity using plasma $(50 \mu \mathrm{L})$, cell lysates $(20 \mu \mathrm{g})$, and kidney lysates $(50 \mu \mathrm{g})$ was assessed as described elsewhere with some modifications [22]. The fluorescence intensity of amido-4methylcoumarin released by the enzymatic activity was monitored every $20 \mathrm{~s}$ for $5 \mathrm{~min}$ or $15 \mathrm{~min}$ at ex. $360 \mathrm{~nm} / \mathrm{em}$. $465 \mathrm{~nm}$ using a spectrofluorometer (Infinite M1000, TECAN, Grödig, Austria) set at $25^{\circ} \mathrm{C}$.

\section{Phospho-kinase array}

Human podocyte lysates $(300 \mu \mathrm{g})$ were analyzed using a Proteome Profiler ${ }^{\mathrm{TM}}$ array (\#ARY003B, R\&D Systems, Minneapolis, USA) according to the manufacturer's instructions. A total of 45 phosphorylation sites were analyzed at a time and images were obtained using a ChemiDoc ${ }^{\mathrm{TM}} \mathrm{XRS}+$ system (Bio-Rad, Hercules, USA).

Table 1. Information on primers and probes used

\begin{tabular}{|c|c|c|c|}
\hline $\begin{array}{l}\text { Target gene } \\
\text { (Symbol) }\end{array}$ & Accession No. & Primers & Size (bp) \\
\hline \multicolumn{4}{|c|}{ Human genes } \\
\hline $\begin{array}{l}\text { Nephrin } \\
(N P H S 1)\end{array}$ & AF035835 & $\begin{array}{l}\text { F: 5'-TCG TGT CTC CCA GAG TGA-3' } \\
\text { R: 5'-ACG TTT GCA GAG ATG TCA GA-3', }\end{array}$ & 196 \\
\hline $\begin{array}{c}\text { DPP4 } \\
(D P P 4)\end{array}$ & NM_001935 & $\begin{array}{l}\text { F: 5'-AGG AGC TGT GAA TCC AAC TG-3' } \\
\text { R: 5'-TTT CTT GTG TTG CCC ATG TC-3' }\end{array}$ & 152 \\
\hline $\begin{array}{l}\text { 18S rRNA } \\
(R N 18 S)\end{array}$ & X03205 & \multicolumn{2}{|c|}{$\begin{array}{l}\mathrm{P} / \mathrm{N} 4308329 \text {, commercialized ABI's ribosomal RNA control } \\
\text { reagents }\end{array}$} \\
\hline \multicolumn{4}{|l|}{ Mouse genes } \\
\hline $\begin{array}{l}\text { Nephrin } \\
(\text { Nphsl) }\end{array}$ & NM_019459 & $\begin{array}{l}\text { F: 5'-CAG GAC CTC CTG TCA TTG AT -3' } \\
\text { R: 5'-TTC AGG TCG AAC GGT CAT -3' }\end{array}$ & 209 \\
\hline $\begin{array}{l}\text { DPP4 } \\
(D p p 4)\end{array}$ & BC022183 & $\begin{array}{l}\text { F: 5'- TTG TGG ATA GCA AGC GAG TTG -3', } \\
\text { R: 5'- CAC AGC TAT TCC GCA CTT GAA -3' }\end{array}$ & 90 \\
\hline $\begin{array}{l}\text { VEGF-A } \\
(\text { Vegfa })\end{array}$ & ВC061468 & $\begin{array}{l}\text { F: 5'-TAC TGC TGT ACC TCC ACC-3' } \\
\text { R: 5'-TCA CTT CAT GGG ACT TCT GCT } \\
\text { CT-3' }\end{array}$ & 78 \\
\hline $\begin{array}{c}\text { 18S rRNA } \\
(\text { Rn18s })\end{array}$ & NR_003278 & $\begin{array}{l}\text { F: 5'-CGG CTA CCA CAT CCA AGG AA-3' } \\
\text { R: 5'-GCT GGA ATT ACC GCG GCT-3' }\end{array}$ & 187 \\
\hline
\end{tabular}




\section{Cellular caspase-3/7 activity assay}

At the end of treatment, Caspase-Glo $3 / 7$ Substrate dissolved in Caspase-Glo 3/7 Buffer (\#G8091, Promega, Madison, USA) was added to each well containing cells in the same volume as the medium and incubated with cells for 30 minutes at room temperature with gentle shaking. Luminescence intensity was measured using a luminometer (LmaxII384, Molecular Devices Inc., Sunnyvale, USA).

\section{Statistical analysis}

The data are expressed as the means \pm SEM. Statistical analyses were performed using SigmaStat 2.0 software (SPSS, Chicago, IL, USA). Comparisons between two groups were conducted using Student's t-test. Multiple comparisons were performed via one-way analysis of variance (ANOVA). For comparisons of data at different time points from the same animals among more than three groups, we used repeated measures (RM) two-way ANOVA. When ANOVA indicated significant differences among groups, these differences were evaluated via a Bonferroni post hoc test or Tukey's multiple comparison test. $\mathrm{p}$ values under 0.05 were considered significant.

\section{Results}

\section{Evogliptin inhibits nephropathy in type 1 diabetic mice}

We first compared the reno-protective effect of evogliptin with two reference drugs in two different diabetic mouse models. The STZ-induced diabetic mouse model is characterized by non-obese and insulin-dependent hyperglycemia. After a 3-month treatment period, albuminuria in STZ mice remarkably deteriorated (Figure 1). Daily urinary albumin excretion reached submaximal levels at week 6, and similar or higher levels were present at week 12. Treatment with irbesartan, an angiotensin II receptor blocker (ARB), or linagliptin significantly lowered albuminuria progression compared with the STZ control. Evogliptin treatment also drastically suppressed albuminuria with efficacy comparable with that of other treatments. This effect was also supported by reduced mesangial expansion (Figure 1). Urinary nephrin excretion trended higher in the STZ control than in the normal control ( $\mathrm{p}=0.065)$, indicating increased podocyte damage in STZ mice (Supplementary Figure 1). Irbesartan and evogliptin alone tended to decrease urinary nephrin excretion $(-27 \%$ and $-39 \%$, respectively), but the observed difference did not achieve statistical significance, likely due to huge individual differences. In line with the trend in urinary nephrin excretion, renal nephrin levels in the STZ control group stayed lower at nearly $70 \%$ those in the normal control group, and evogliptin and linagliptin alone showed a tendency to restore levels but the difference fell short of statistical significance (Supplementary Figure 1). These results show that evogliptin has efficacy comparable to that of ARBs in preventing the progression of $\mathrm{DN}$.

\section{Evogliptin inhibits nephropathy in type 2 diabetic mice}

Typically, $\mathrm{db} / \mathrm{db}$ mice exhibit hyperglycemia accompanied by obesity and severe insulin resistance. At the end of the experiment, 19-week-old $\mathrm{db} / \mathrm{db}$ mice displayed typical proteinuria with two times higher urine protein levels than those in the normal control group $(p<0.01)$ (Figure 2). Twelve weeks of treatment with irbesartan or evogliptin at a high dose significantly reduced the progression of proteinuria $(-23.2 \%$ or $-22.7 \%$, respectively; $\mathrm{p}<0.05)$, but linagliptin treatment showed a marginal reduction of $-9.3 \%$.

Along with the progression of proteinuria, at the end of experiment, urinary nephrin excretion in the $\mathrm{db} / \mathrm{db}$ control mice was approximately 5 times higher than the baseline and that of normal controls of the same age $(\mathrm{p}<0.05)$ (Figure 2$)$. Interestingly, as a biomarker of podocyte damage, urinary nephrin levels were higher in $\mathrm{db} / \mathrm{db}$ mice than in the STZ-induced diabetic mouse model. Nevertheless, evogliptin treatment significantly blocked the

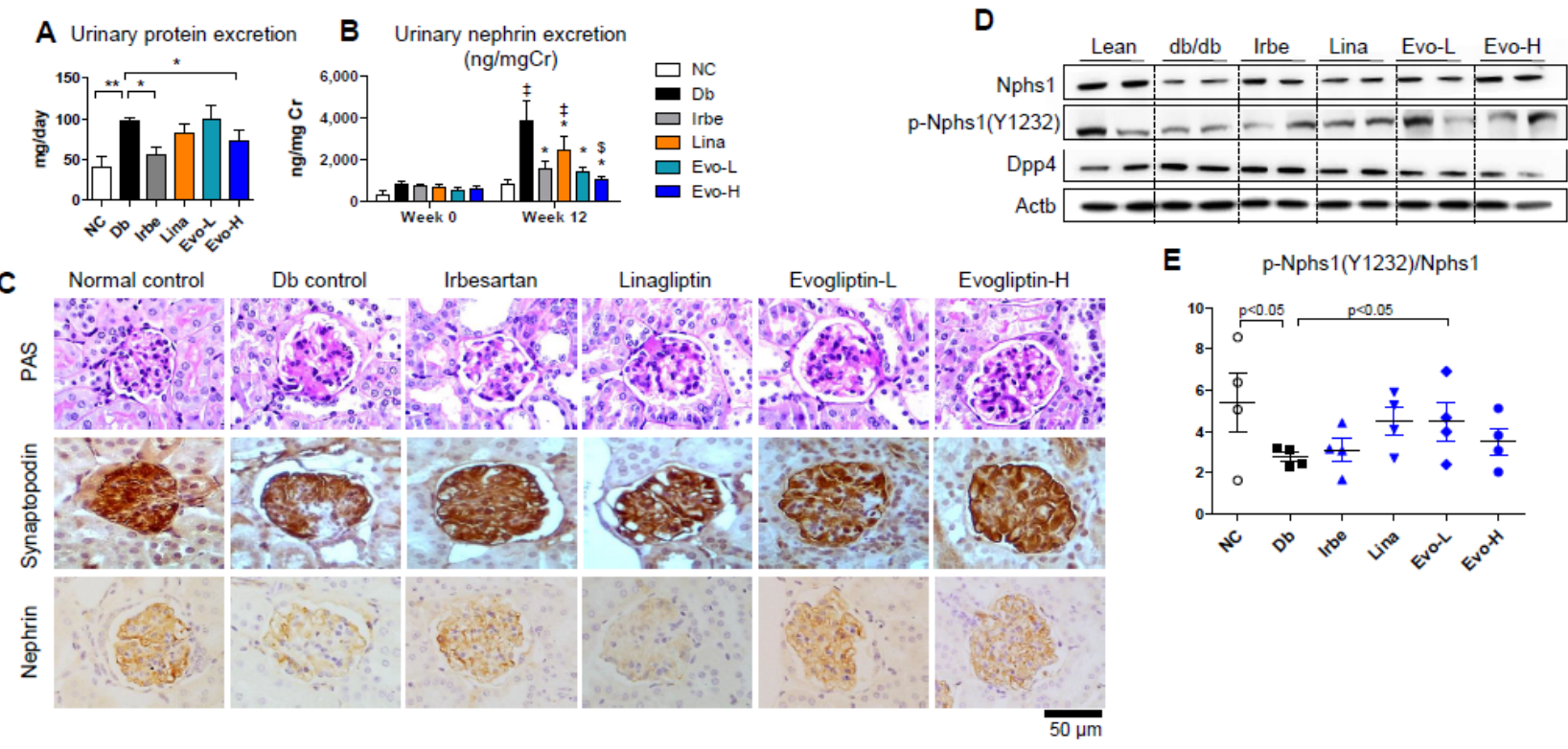

Figure 2. Effects on diabetic nephropathy in $\mathrm{db} / \mathrm{db}$ mice. Seven-week-old $\mathrm{db} / \mathrm{db}$ mice were given a repelleted diet with or without each drug for $12 \mathrm{weeks}$ as follows: $\mathrm{NC}$, normal control; $\mathrm{Db}$, $\mathrm{db} / \mathrm{db}$ control; Irbe, $50 \mathrm{mg} / \mathrm{kg} /$ day irbesartan; Lina, $3 \mathrm{mg} / \mathrm{kg} /$ day linagliptin; Evo-L, $100 \mathrm{mg} / \mathrm{kg} /$ day evogliptin; Evo-H, $300 \mathrm{mg} / \mathrm{kg} / \mathrm{day}$ evogliptin. After $12 \mathrm{weeks} \mathrm{of} \mathrm{treatment,} 24-\mathrm{h}$ urinary protein excretion was assessed by total protein concentrations and urine volume (A). Urinary nephrin excretion was evaluated before and after treatment (B). Kidney sections were stained to evaluate mesangial expansion and podocyte damage; representative images are shown of PAS-stained kidney sections and kidney sections stained immunohistochemically with specific antibodies against synaptopodin or nephrin (original magnification x200) (C). Protein levels of nephrin, phosphorylated nephrin at Y1232, and DPP4 were evaluated in kidney lysates via immunoblotting (D). The ratio of phospho-nephrin (Y1232) to nephrin in kidney lysates was calculated based on image analysis (E). *, p $<0.05 \mathrm{vs} \mathrm{normal} \mathrm{control;} \mathrm{*,}<<0.05 \mathrm{vs} \mathrm{db} / \mathrm{db}$ control; $\$, \mathrm{p}<0.05$ vs Lina (determined by RM two-way ANOVA) 
development of nephrinuria, even at a lower dose $(-64.1 \%$ and $-73.4 \%$ at 100 and $300 \mathrm{mg} / \mathrm{kg} /$ day, respectively; $\mathrm{p}<0.05 \mathrm{vs}$. $\mathrm{db} / \mathrm{db}$ control), with efficacy comparable to irbesartan $(-69.8 \%$; $<<0.05)$. Meanwhile, linagliptin showed a mild abatement of $-40.9 \%(\mathrm{p}<0.05)$ compared with the $\mathrm{db} / \mathrm{db}$ control group.

Histopathologic detection showed that evogliptin treatment suppressed mesangial expansion and preserved renal expression of podocytic proteins, such as nephrin and synaptopodin, in the glomeruli of $\mathrm{db} / \mathrm{db}$ mice (Figure 2). This pattern was recapitulated in the immunoblot analysis results. In renal tissue, nephrin protein levels were reduced in the $\mathrm{db} / \mathrm{db}$ control but were preserved in ARBor evogliptin-treated groups (Figure 2). In addition, nephrin tyrosine phosphorylation was altered in a similar manner. Of note, the ratio of the phosphorylated nephrin level to total nephrin level was significantly lower in the $\mathrm{db} / \mathrm{db}$ control group than in the normal control group and was restored by evogliptin treatment (Figure 2). Meanwhile, irbesartan failed to show a marked effect on the phospho-nephrin ratio, suggesting potential differences in the mechanisms underlying the renoprotective effect. Additionally, renal DPP4 protein levels slightly increased in the $\mathrm{db} / \mathrm{db}$ control and tended to decrease after treatment with DPP4 inhibitors. At the end of the experiments, the $\mathrm{db} / \mathrm{db}$ mice exhibited prominent obesity, polydipsia and polyuria. Absolute kidney weight increased significantly, but relative kidney weight to body weight trended lower without statistical significance. However, none of treatments significantly affected body weight, kidney weight, water intake or urine volume (Table 2).

These results suggest that evogliptin prevents nephropathy progression by protecting against podocyte injury and nephrin loss.

\section{Podocyte-protective effect of evogliptin is independent of glucose control}

Although the urinary albumin excretion rate was significantly alleviated in STZ mice by treatment with DPP4 inhibitors, plasma glucose levels were not altered by any treatments, with average levels of $40-50 \mathrm{mmol} / \mathrm{l}$ and no significant difference between treatment groups (Supplementary Figure 1). In addition, as published elsewhere, DPP4 inhibitors did not improve hyperglycemia in old $\mathrm{db} / \mathrm{db}$ mice with severe insulin resistance (Figure 3). Meanwhile, DPP4 activity in plasma and renal tissue significantly increased in $\mathrm{db} / \mathrm{db}$ mice compared with that in normal control mice. In accordance with the mode of action, linagliptin $(-81.7 \%$ vs $\mathrm{db} / \mathrm{db}$ control; $\mathrm{p}<0.05)$ or evogliptin $(-89.6$ and $-97.6 \%$ at 100 and $300 \mathrm{mg} / \mathrm{kg} /$ day, respectively; $\mathrm{p}<0.05)$ treatment showed over $80 \%$ inhibition of plasma DPP4 activity, which is in accordance with the daily effective dose of DPP4 inhibitors used for glucose regulation in the clinic, but irbesartan did not (Figure 3). On the other hand, renal DPP4 activity was significantly lower in all treatment groups than in the $\mathrm{db} / \mathrm{db}$ control group and was even decreased by irbesartan treatment
$(-16.4 \%$ inhibition; $\mathrm{p}<0.05)$, which suggests incidental change following a direct renal protective effect in addition to chronic metabolic or hemodynamic improvement induced by irbesartan (Figure 3).

These findings suggest that the reno-protective effects of evogliptin treatment does not result from an indirect effect related to metabolic improvement, such as glucose regulation.

\section{Effects of evogliptin on podocytic protein expression in vitro}

To explore the effects of evogliptin on various podocytic proteins in diabetes and to distinguish them from GLP-1-dependent systemic effects, differentiated mouse podocytes were treated with drugs under conditions that mimic diabetes, namely, with $30 \mathrm{mM}$ glucose and $100 \mathrm{nM}$ angiotensin II (HG+AngII). After a 72-h treatment of mouse podocytes, cellular DPP4 activity was significantly increased by HG+AngII, while evogliptin treatment reduced cellular DPP4 activity in a concentration-dependent manner, but linagliptin did not (Figure 4). Interestingly, after treatment, cellular DPP4 protein levels did not change significantly regardless of treatments (Figure 4), which suggests that reduced DPP4 activity may be attributed to post-translational regulation, such as inhibition of enzymatic activity due to nondissociated evogliptin or inhibition of enzymatic activation through interference with DPP4 enzyme dimerization.

In differentiated mouse podocytes, each treatment altered nephrin protein levels in a different manner (Figure 4). HG+AngII decreased the average cellular nephrin protein by $31.9 \%$ ( $\mathrm{p}<0.05$ vs the normoglucose control). Evogliptin treatment with HG+AngII completely blocked nephrin loss in a concentration-dependent manner from $10 \mathrm{nM}(\mathrm{p}<0.05$ vs HG+AngII control), while linagliptin treatment was ineffective.

The changes in podocalyxin protein engaged in the foot processes of podocytes and the patency of the filtration slits [23], were similar to those observed in nephrin levels (Figure 4). But, WT-1 protein expression as a transcription factor regulating podocalyxin expression [24], was not altered by HG+AngII regardless of the presence of any DPP4 inhibitor (Figure 4). In line with the report indicating that defects in VEGFA secretion by podocytes are associated with renal failure [25], HG+AngII tended to decrease podocytic VEGFA expression, and only evogliptin treatment showed a tendency to restore it, but none of the changes reached statistical significance (Figure 4).

These results suggest a direct protective effect of evogliptin against the loss of key functional proteins in differentiated podocytes.

\section{Evogliptin prevents nephrin loss via post-transcriptional regulation}

Next, we examined whether the reduction in nephrin protein levels induced by HG+AngII in differentiated mouse podocytes was caused by transcriptional downregulation. In the result, $\mathrm{HG}+$ AngII did not

Table 2. Body weight, kidney weight, water intake, and urine volume after 12 weeks of treatment in $\mathrm{db} / \mathrm{db}$ mice a, $\mathrm{p}<0.05 \mathrm{vs}$. normal control

\begin{tabular}{|c|c|c|c|c|c|c|c|}
\hline & & Normal control & Db control & Irbe & Lina & Evo-L & Evo-H \\
\hline$N$ & & 8 & 8 & 8 & 8 & 8 & 8 \\
\hline \multirow{2}{*}{$\begin{array}{l}\text { Body weight } \\
\text { (g) }\end{array}$} & WO & $21.9 \pm 0.3$ & $33.9 \pm 0.8^{\mathrm{a}}$ & $34.1 \pm 1.6^{\mathrm{a}}$ & $33.2 \pm 1.1^{\mathrm{a}}$ & $33.6 \pm 0.9^{\mathrm{a}}$ & $33.9 \pm 1.1^{\mathrm{a}}$ \\
\hline & $W 12$ & $29.1 \pm 0.7$ & $52.7 \pm 5.3^{\mathrm{a}}$ & $54.1 \pm 2.2^{\mathrm{a}}$ & $53.2 \pm 3.9^{\mathrm{a}}$ & $54.5 \pm 3.5^{\mathrm{a}}$ & $46.2 \pm 3.7^{\mathrm{a}}$ \\
\hline Absolute kidney weight (g) & & $0.334 \pm 0.012$ & $0.458 \pm 0.041^{\mathrm{a}}$ & $0.440 \pm 0.012^{\mathrm{a}}$ & $0.437 \pm 0.015^{\mathrm{a}}$ & $0.477 \pm 0.021^{\mathrm{a}}$ & $0.403 \pm 0.022$ \\
\hline $\begin{array}{l}\text { Relative kidney weight } \\
(\mathrm{mg} / 100 \mathrm{~g} \mathrm{BW})\end{array}$ & & $1.147 \pm 0.029$ & $0.949 \pm 0.219$ & $0.818 \pm 0.036$ & $0.860 \pm 0.077$ & $0.903 \pm 0.081$ & $0.912 \pm 0.093$ \\
\hline $\begin{array}{l}\text { Water intake } \\
(\mathrm{ml} / \text { day })\end{array}$ & & $7.1 \pm 1.9$ & $19.8 \pm 3.7^{\mathrm{a}}$ & $17.0 \pm 0.1^{\mathrm{a}}$ & $20.1 \pm 0.2^{\mathrm{a}}$ & $20.2 \pm 1.5^{\mathrm{a}}$ & $17.3 \pm 2.4^{\mathrm{a}}$ \\
\hline $\begin{array}{l}\text { Urine volume } \\
(\mathrm{mg} / \text { day })\end{array}$ & & $0.90 \pm 0.16$ & $9.61 \pm 0.84^{\mathrm{a}}$ & $6.36 \pm 0.86^{\mathrm{a}}$ & $9.20 \pm 1.08^{\mathrm{a}}$ & $10.41 \pm 1.58^{\mathrm{a}}$ & $8.27 \pm 0.91^{\mathrm{a}}$ \\
\hline
\end{tabular}




\section{A Plasma glucose}

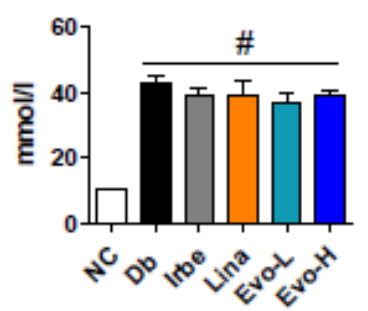

B Plasma DPP4 activity

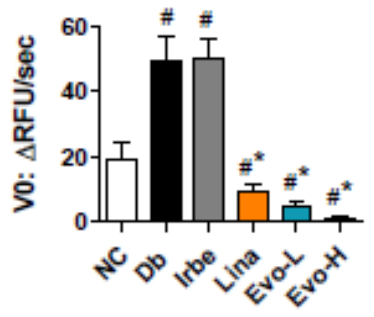

C Renal DPP4 activity

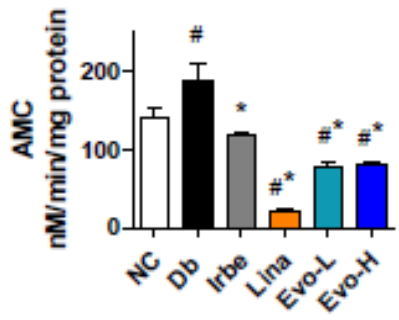

Figure 3. Effects on plasma glucose, plasma and renal DPP4 activity in db/db mice. After 12 weeks of treatment, plasma glucose levels were determined (A). Plasma DPP4 activity (B) and DPP4 activity in renal lysates (C) were kinetically assessed at $25^{\circ} \mathrm{C}$ using Gly-Pro-AMC substrate. \#, p $<0.05 \mathrm{vs}$ normal control; *, p $<0.5 \mathrm{vs} \mathrm{db} / \mathrm{db}$ control (determined by one-way ANOVA)

\section{Mouse podocytes}

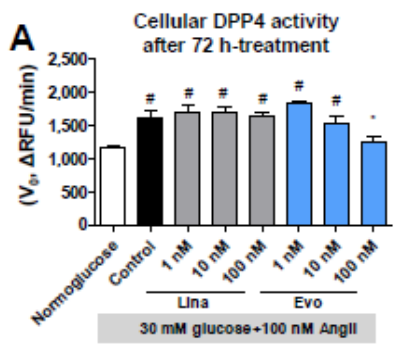

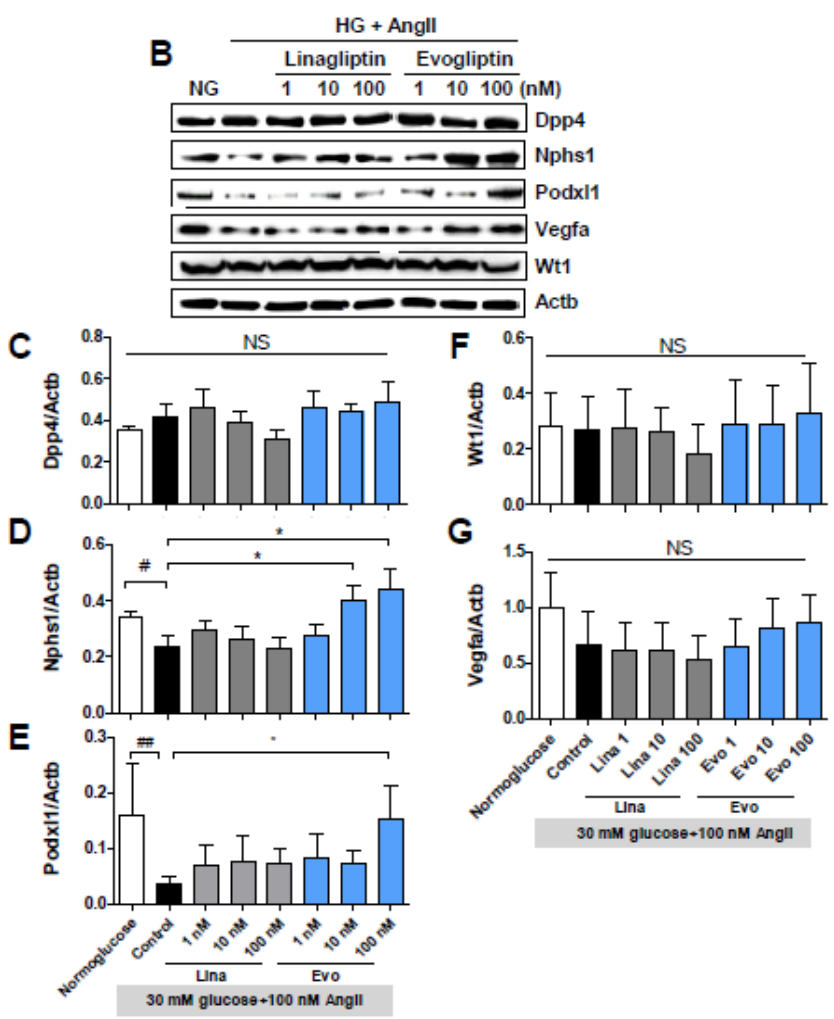

Figure 4. Effects on differentiated mouse podocytes. Differentiated mouse podocytes were treated with evogliptin or linagliptin combined with $30 \mathrm{mM}$ glucose and $100 \mathrm{nM}$ angiotensin II (HG+AngII). After $72 \mathrm{~h}$ of treatment, DPP4 activity in cell lysates was accessed at $25^{\circ} \mathrm{C}$ using Gly-Pro-AMC as the substrate (A). Cellular protein levels of DPP4, nephrin (Nphs1), podocalyxin (Podx11), VEGF-A (Vegfa), and Wilms Tumor Protein (Wt1) were assessed via immunoblot analyses. Representative gel images (B) and quantitative analysis results for three individual determinants $(\mathrm{C})$. \#, $\mathrm{p}<0.05$ vs normoglucose control; *, $\mathrm{p}<0.05$ vs HG+AngII control (determined by one-way ANOVA)

elicit any significant alteration in mRNA expression of not only nephrin and but also VEGFA (Supplementary Figure 2). This phenotype was recapitulated by $\mathrm{HG}+$ AngII in human primary podocytes, in which the gene expression of nephrin stayed constant but the reduction in nephrin protein levels induced by HG+AngII was pronounced (Supplementary Figure 2).

To determine precise modes of action, we used primary human podocytes [21]. First, we tested if linagliptin or evogliptin treatment would elicit the same response in the regulation of nephrin and DPP4 protein levels in human podocytes compared with mouse podocytes. In agreement with the results in mouse podocytes, HG+AngII-treated human podocytes exhibited reduced nephrin protein levels, which were $60 \%$ those observed in normoglucose control cells $(-40 \%, \mathrm{p}<0.05)$ (Figure 5). On the other hand, evogliptin treatment at $100 \mathrm{nM}$ led to 1.76 times higher nephrin protein levels than those in $\mathrm{HG}+$ AngII control cells, and the increase was concentration dependent ( $\mathrm{p}=0.056)$ (Figure 5), indicating complete preservation of cellular nephrin levels. Linagliptin did not show any significant protective effect on nephrin levels. As in mouse podocytes, none of the treatments affected the cellular DPP4 protein levels in human podocytes. Moreover, mRNA levels of nephrin and DPP4 were not altered by any of the treatments (Figure 5). Changes in cellular DPP4 activity also presented the same pattern observed in mouse podocytes, but the observed inhibition induced by $100 \mathrm{nM}$ evogliptin failed to reach significance (-13.4\%, $\mathrm{p}=0.095$ ) (Figure 5). 
Next, we investigated whether the nephrin-protective effect of evogliptin required protein synthesis. In the presence of the protein synthesis inhibitor cycloheximide, the nephrin loss induced by HG+AngII disappeared, and evogliptin treatment did not induce prominent changes compared with the HG+AngII control (Figure 5). Overall, evogliptin completely prevented nephrin loss in both mouse and human podocytes through post-transcriptional regulation rather than transcriptional changes.

\section{Evogliptin prevents apoptotic podocyte death by relieving stress signals}

To define the cellular signaling involved in the evogliptin effects, changes in intracellular signal transduction were examined in human podocytes, particularly for 43 kinase phosphorylation sites involved in cellular stress responses.

As expected, a total of 12 phosphorylation sites (p38, ERK, JNK, GSK-3 $\alpha / \beta$, MSK, AMPKa1, AKT-S473, AKT-T308, p53, HSP27), including in three prototypical stress-related mitogen-activated protein (MAP) kinases, were more phosphorylated under HG+AngII conditions than under normoglucose control conditions (Figure 6). However, there was no change in the phosphorylation levels of STATs, the mTOR/S6 kinase pathway, RSK/CREB, or src family enzymes (Fyn, Yes, and Lyn kinases) (data not shown). Notably, after evogliptin treatment, the enhanced phosphorylation levels observed in three typical stress-responsive MAP kinases (p38, ERK, and JNK) trended down. Similarly, evogliptin reduced the phosphorylation levels of downstream substrates, such as MSK1/2 and c-Jun for ERK/p38 and JNK, respectively. Additionally, the phosphorylation of AKT1/2/3 at S473 and T308 and of p53 at S46 that increased under HG+AngII conditions was normalized by evogliptin treatment.
Next, we investigated whether evogliptin can mitigate apoptotic intracellular signaling transduction in differentiated mouse podocytes by attenuating the cellular stress response. In our results, compared with the normoglucose control group, HG+AngII treatment increased cellular caspase-3/7 activity, the main executioner enzymes during apoptotic death, with marginal significance $(\mathrm{p}=0.07)$, which tended to be normalized by $100 \mathrm{nM}$ evogliptin ( $\mathrm{p}=0.063$ vs. HG+AngII control) (Figure 6). Likewise, the cleaved caspase-3 protein level was increased by $\mathrm{HG}+$ AngII, and its reduction by evogliptin treatment was prominent (Figure 6). Subsequently, proteolytic cleavage of PARP, a substrate of caspase-3, changed in proportion to activated caspase-3 levels, and evogliptin treatment blocked the proteolytic inactivation of PARP induced by HG+AngII. In summary, evogliptin treatment rendered podocytes less sensitive to the HG+AngII-induced apoptotic signal.

\section{Evogliptin prevents shedding of membrane DPP4}

Then, we postulated that evogliptin could protect podocytes from death by blocking DPP4 shedding. To understand the effect of evogliptin on DPP4 shedding, DPP4 protein levels in conditioned medium and cell lysates of differentiated mouse podocytes were measured. Interestingly, DPP4 levels shed into media were significantly (2.35 times) higher in the HG+AngII group than in the normoglucose control group $(\mathrm{p}<0.05)$, while cellular DPP4 levels remained constant, which is in line with the previous report [26] (Figure 7). Notably, evogliptin treatment completely blocked DPP4 shedding in differentiated mouse podocytes $(-69.3 \%$ inhibition vs. HG+AngII, $\mathrm{p}<0.05)$. Then, we tested the engagement of caveolin-1-mediated endocytosis in nephrin preservation. In human podocytes, treatment of an endocytosis inhibitor nystatin abolished nephrin loss caused by HG+AngII. These results indicate for the first time that stress-induced DPP4 shedding per se can be inhibited by a
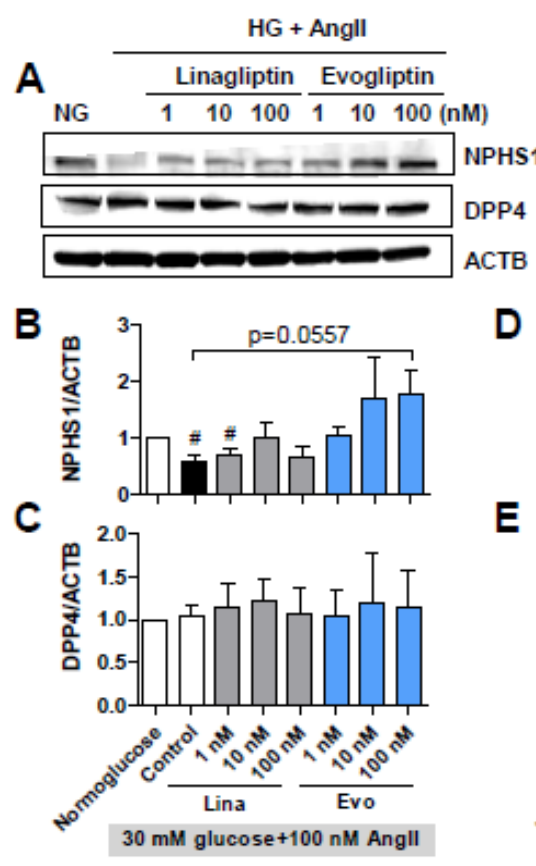

E
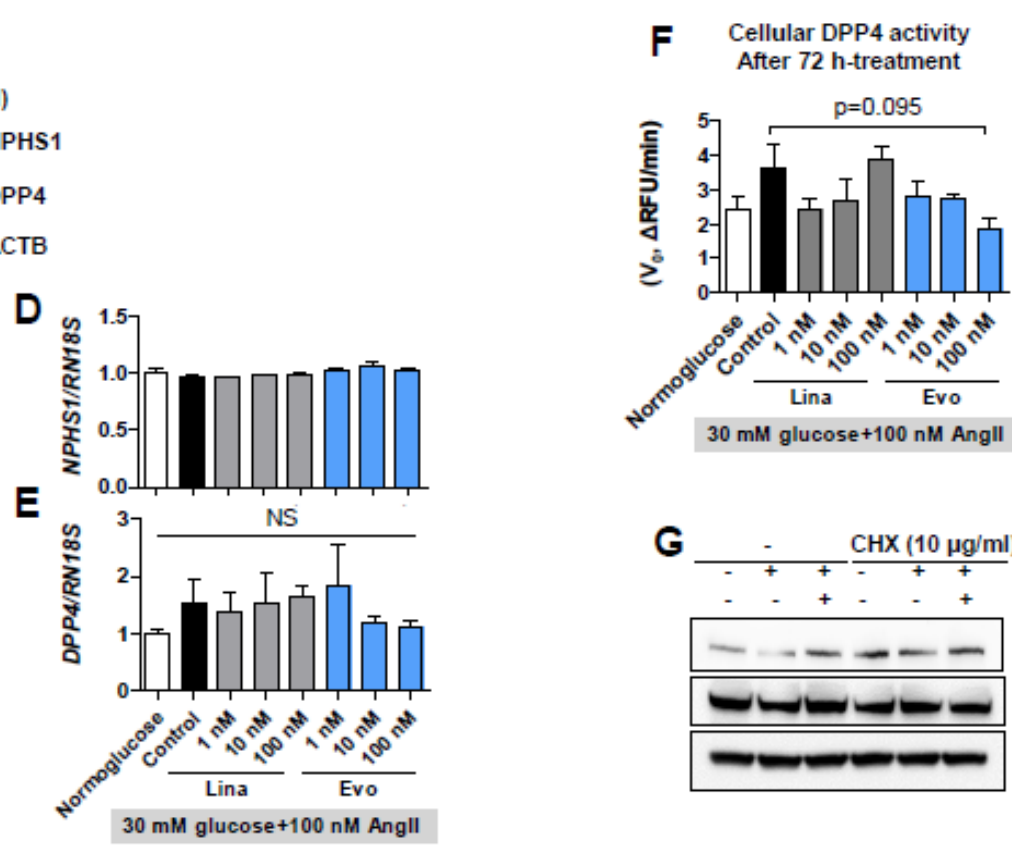

G

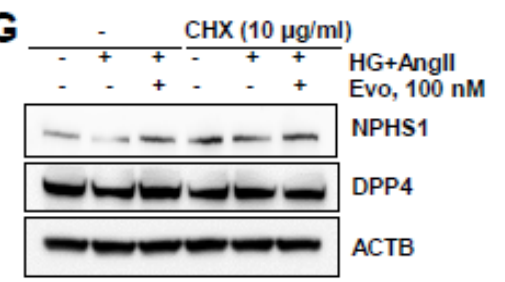

Figure 5. Effects on primary human podocytes. Human podocytes were treated with evogliptin or linagliptin combined with $30 \mathrm{mM}$ glucose and $100 \mathrm{nM}$ angiotensin II (HG+AngII). After 72 $\mathrm{h}$ of treatment, cellular protein levels of nephrin (NPHS1) and DPP4 were determined by immunoblotting. Representative images (A) and quantitative analytical results for three individual determinants (B, C). Cellular mRNA levels of nephrin (NPHSI) and DPP4 were assessed via qPCR (D, E). DPP4 activity in lysates was measured at $25^{\circ} \mathrm{C}$ using Gly-Pro-AMC substrate (F). Effects of cycloheximide (CHX, $10 \mu \mathrm{g} / \mathrm{ml}$ ) exposure for the last 24 hours of treatment on the podocytic proteins nephrin (NPHS1) and DPP4 were determined by immunoblotting (G) 

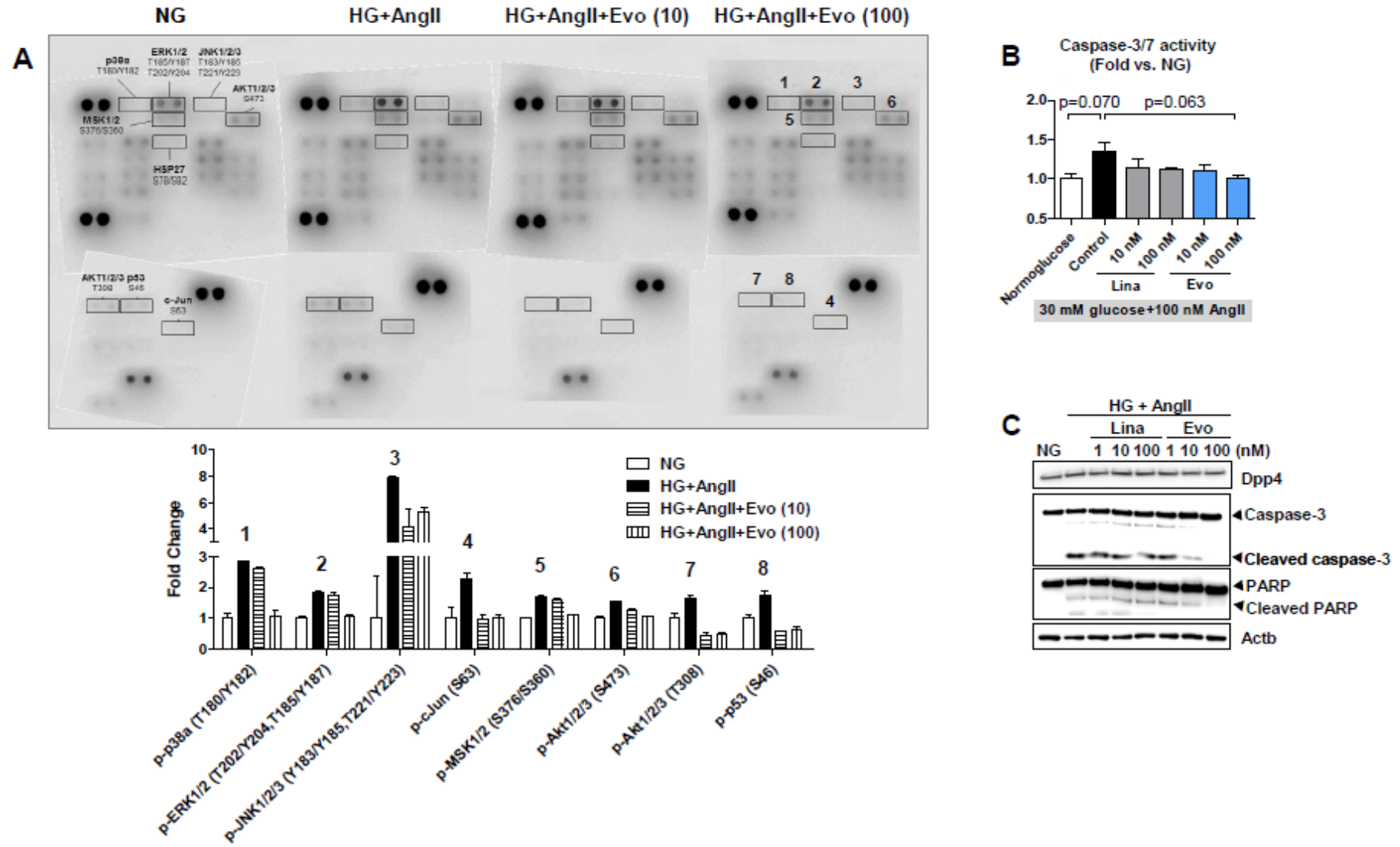

Figure 6. Effects on cellular stress responses in human podocytes. After $72 \mathrm{~h}$ of treatment with $30 \mathrm{mM}$ glucose and $100 \mathrm{nM}$ angiotensin II (HG+AngII) in the absence or presence of evogliptin, lysates of human podocytes were incubated with phospho-kinase array membranes, and 45 phosphorylated proteins were visualized using a specific antibody cocktail system. Representative image and quantitative analysis data of eight phosphorylated proteins altered by evogliptin treatment from two different experiments (A). After $72 \mathrm{~h}$ of treatment with HG+AngII in the absence or presence of evogliptin or linagliptin, cellular caspase-3/7 activity in differentiated mouse podocytes was assessed using a Capase-Glo ${ }^{\circledR} 3 / 7$ Assay System (B). In addition, cellular protein levels of caspase-3, cleaved active caspase-3, PARP and cleaved inactive PARP were determined via immunoblotting (C)

A

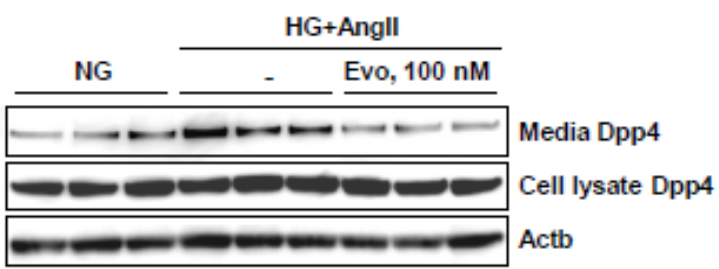

Media Dpp4 Cellular Dpp4

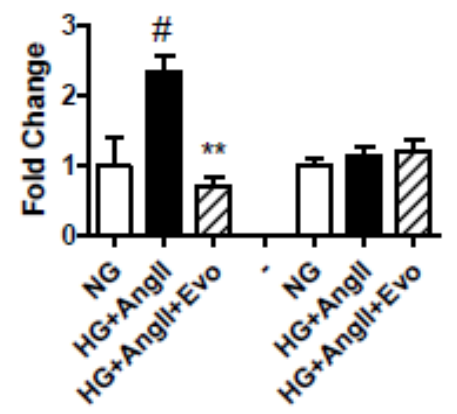

B

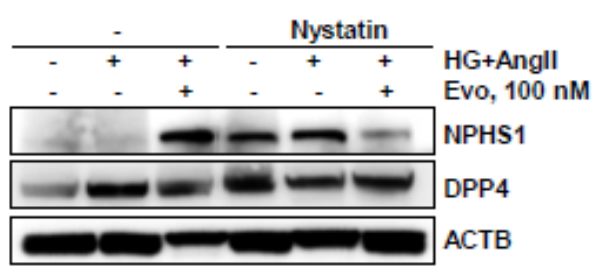

Figure 7. Effects on DPP4 shedding and effects of endocytosis inhibition. After treatment of differentiated mouse podocytes for $72 \mathrm{~h}$, the protein levels of cellular DPP4 and DPP4 shed into the medium were determined via immunoblotting. Image and quantitative image analysis data from three individual determinants (A). In human podocytes, cellular protein levels of nephrin (NPHS1) and DPP4 were evaluated after $72 \mathrm{~h}$ of treatment in the presence or absence of pretreatment of nystatin (50 $\mu \mathrm{g} / \mathrm{ml})$, an endocytosis inhibitor from $30 \mathrm{~min}$ before drug treatment (B). $\#, \mathrm{p}<0.05$ vs normoglucose control; ${ }^{* *}, \mathrm{p}<0.01$ vs $\mathrm{HG}+$ AngII control (determined by one-way ANOVA) 
DPP4 inhibitor without a change in DPP4 expression in differentiated podocytes.

\section{Discussion}

In this study, we demonstrated the direct protective effects of evogliptin on podocytes. Evogliptin inhibited membrane DPP4 shedding from podocytes in the presence of HG+Ang II without changes in intracellular DPP4 expression levels and attenuated cellular stress responses, including MAP kinase signaling. Therefore, evogliptin treatment attenuated the progression of $\mathrm{DN}$ by preserving podocyte nephrin levels and preventing apoptotic death, thereby preventing podocyte loss. Last, our results support the potential clinical implication: Evogliptin is comparable to ARBs in attenuating DN and is superior to linagliptin in preservation of podocyte nephrin.

Podocyte loss due to cell death, detachment and/or epithelial-tomesenchymal transition contributes to the pathogenesis of DN [27]. Multiple lines of evidence suggest that renin-angiotensin system (RAS) activation is involved in the development of type 2 diabetes [28]. Likewise, sustained high glucose and/or RAS activation can lead to cell death in differentiated podocytes via oxidative stress and endoplasmic reticulum stress [29-32]. In a previous report, evogliptin treatment completely blocked cell death caused by HG+AngII in differentiated mouse podocytes [14], but to date, the underlying mechanism remains unexplored. Membrane-bound DPP4 localizes preferentially to the membrane of the podocyte foot process and slit diaphragm [12]. DPP4 expression is drastically higher in podocytes than in mesangial cells and DPP4 inhibition suppresses podocyte growth in immortalized human podocytes via blocking of stromal cell-derived factor-1 (SDF-1)[15]. This evidence supports the potential role of DPP4 in the regulation of podocyte cell biology, just as endothelial DPP4 expression controls endothelial-mesenchymal transition $[33,34]$.

Our study indicates differential effects of two DPP4 inhibitors on podocytes. Evogliptin lowered cellular DPP4 activity without altering DPP4 expression levels, while linagliptin failed to reduce cellular DPP4 activity. Likewise, only evogliptin treatment preserved nephrin levels in podocytes under diabetic conditions. However, we did not fully clarify whether inhibition of enzymatic activity is a prerequisite for the nephrin-protective effects. In contrast, in endothelial cells, linagliptin has been found to inhibit DPP4 activity by reducing DPP4 expression and homodimerization caused by tumor growth factor $\beta$ (TGF $\beta$ ), whereas sitagliptin, another DPP4 inhibitor, failed to block TGF $\beta$ induced DPP4 expression and activation [33]. These findings suggested for the first time a unique compound-specific effect rather than a class effect of DPP4 inhibitors on cell biology, which can be understood considering different inhibitor binding modes due to differences in their chemical backbone [35]. However, in our study, DPP4 expression was not altered by HG+Ang II. That seems to be a major discrepancy in the regulation of DPP4 in both cell systems under different stress conditions. Meanwhile, both linagliptin and sitagliptin have shown to inhibit DPP4 activity in human podocyte lysates and suppress cellular growth in immortalized human podocytes via blocking of SDF-1 [15], although there are no reports on its effect on DPP4 expression in podocytes. These findings indicate that linagliptin works successfully in podocytes but support the notion that there may be potential discrepancies between endothelial cells and podocytes in the regulation of DPP4 expression/activation and the action of DPP4 inhibitors. Thus, further study is needed to define how DPP4 expression and activity is regulated and determine the role of DPP4 in podocytes.

To the best of our knowledge, there are no reports on soluble DPP4 shed from podocytes. In our study, following combined treatment with high glucose and angiotensin II, podocytes shed more DPP4 into the medium, and evogliptin inhibited the DPP4 release. Several reports have shown a contribution of soluble DPP4 to the progression of certain diseases. The origin of plasma DPP4 was reported to be endothelial cells, hepatocytes, adipocytes and immune cells, while the kidneys may not be a major source of circulating soluble DPP4 [3639]. However, local action of soluble DPP4 released from renal cells cannot be ruled out. DPP4 shedding was increased by high glucose, advanced glycated end products or hydrogen peroxide in endothelial cells $[40,41]$. Meanwhile soluble DPP4 led to the generation of reactive oxygen species in endothelial cells through interaction with mannose 6-phosphate/insulin-like growth factor II receptor (M6P/IGFIIR) [41]. Then, activation of the redox-sensitive transcription factor nuclear factor kappa-light-chain-enhancer of activated B cells (NF-kB) results in subsequent intercellular adhesion molecule (ICAM)- 1 and plasminogen activator inhibitor (PAI)-1 gene induction, which drives inflammation and fibrosis. Protease-activated receptor 2 (PAR2) is another membrane protein proposed to mediate soluble DPP4 action such as activation of ERK and NF-kB, cell proliferation, and induction of pro-inflammatory cytokines [37,42]. DPP4-induced inflammation and insulin resistance disappeared after silencing of caveolin-1 or PAR2 in adipose tissue macrophages [37]. On the other hand, soluble DPP4 was reported to mediate palmitate-induced cell death in cardiac progenitor cells [26]. In our study, caveolin-1-mediated endocytosis was shown to mediate the nephrin-protective effects of evogliptin, which has been reported elsewhere [37]. Therefore, further study to define the membrane counterpart of soluble DPP4 is worth conducting. Meanwhile, linagliptin and teneligliptin inhibited DPP4 release from endothelial cells, but their inhibition of DPP4 shedding was not completely distinct from the downregulation of DPP4 expression, unlike evogliptin $[40,41]$. Despite some discrepancy in cell biology between endothelial cells and podocytes, we presumed that the inhibition of soluble DPP4 release by evogliptin might contribute to mitigation of podocyte injury by relieving the stress response and oxidative stress.

Urinary nephrin loss is a biomarker of early glomerular injury because podocytes regulate glomerular permeability selectivity through the slit diaphragm, a specialized cell-cell junction primarily consisting of physically connected nephrin and cytoskeletal actin proteins [43]. A tyrosine residue at 1217 in the intracellular region of human nephrin is conserved between humans, mice (1232-YDQV), and rats (1228-YDQV) and is present in YDxV motifs [44]. Previously, there was conflicting speculation regarding increased nephrin phosphorylation in renal injury $[45,46]$; however recently, Jones $\mathrm{N}$, et al. put an end to the controversy by demonstrating that overall loss of nephrin phosphorylation is a causative factor in renal dysfunction [44]. Consistently, our findings suggest that nephrin levels in podocytes are regulated post-transcriptionally and the phospho-nephrin (Y1232)to-nephrin ratio is reduced in DN mice. Nephrin is known to be phosphorylated by src family kinases [45], but the activation levels of src family kinases, such as Src, Fyn, and Yes, were not prominently altered in podocytes under HG+AngII conditions in this study (data not shown). Intriguingly, chronic treatment with evogliptin increased phospho-nephrin levels, while treatment with irbesartan did not. This suggests that DPP4 inhibitors may be a potential therapeutic option for preserving nephrin in podocytes to slow nephropathy progression.

Our data suggest that evogliptin attenuates podocytic stress responses, including kinase signaling cascades and DPP4 shedding, under diabetic conditions, thereby preventing podocyte damage and the progression of nephropathy. Although we cannot fully explain why evogliptin acts differently in podocytes compared to linagliptin, our 
findings may have clinical implications for application of evogliptin in diabetic patients with progressive podocyte injury.

\section{Declarations}

\section{Availability of data and materials}

All data generated or analyzed during this study are included in this published article and its supplementary information file.

\section{Author's contribution}

$\mathrm{JIH}, \mathrm{CYN}$ and $\mathrm{KTH}$ performed animal experiments and analyzed data. LBR performed the histological examination of the kidney. $\mathrm{CYH}$ and $\mathrm{PH}$ conducted podocyte cultures and biochemical evaluation, interpreted the data, and drafted the manuscript. KMK designed experiments, analyzed and interpreted the data and wrote the manuscript. All authors read and approved the final manuscript.

\section{Competing interests}

All authors are employees of Dong-A ST Co., Ltd.

\section{Acknowledgement}

We sincerely appreciate Prof. Dae Ryong Cha at Korea University Ansan Hospital providing technical advice and support.

\section{Funding}

All studies described in the publication were funded by Dong-A ST Co. Ltd.

\section{References}

1. Coresh J, Astor BC, Greene T, Eknoyan G, Levey AS (2003) Prevalence of chronic kidney disease and decreased kidney function in the adult US population: Third National Health and Nutrition Examination Survey. Am J Kidney Dis 41: 1-12. [Crossref]

2. Bailey RA, Wang Y, Zhu V, Rupnow MFT (2014) Chronic kidney disease in US adults with type 2 diabetes: an updated national estimate of prevalence based on kidney disease: Improving global outcomes (KDIGO) staging. BMC Res Notes 7: 415.

3. Siddiqi FS, Advani A (2013) Endothelial-podocyte crosstalk: the missing link between endothelial dysfunction and albuminuria in diabetes. Diabetes 62: 3647-3655.

4. Aaltonen P, Luimula P, Aström E, Palmen T, Grönholm T, et al. (2001) Changes in the expression of nephrin gene and protein in experimental diabetic nephropathy. $L a b$ Invest 81: 1185-1190. [Crossref]

5. Tryggvason K (1999) Unraveling the mechanisms of glomerular ultrafiltration: nephrin, a key component of the slit diaphragm. J Am Soc Nephrol 10: 2440-2445.

6. Neumiller JJ, Wood L, Campbell RK (2010) Dipeptidyl peptidase-4 inhibitors for the treatment of type 2 diabetes mellitus. Pharmacotherapy 30: 463-484.

7. Groop PH, Cooper ME, Perkovic V, Emser A, Woerle HJ, et al. (2013) Linagliptin lowers albuminuria on top of recommended standard treatment in patients with type 2 diabetes and renal dysfunction. Diabetes Care 36: 3460-3468.

8. Yoon SA, Han BG, Kim SG, Han SY, Jo YI, et al. (2017) Efficacy, safety and albuminuria-reducing effect of gemigliptin in Korean type 2 diabetes patients with moderate to severe renal impairment: A 12-week, double-blind randomized study (the GUARD Study). Diabetes Obes Metab 19: 590-598.

9. Hasan AA, Hocher B (2017) Role of soluble and membrane-bound dipeptidyl peptidase-4 in diabetic nephropathy. $J$ Mol Endocrinol 59: 1-10.

10. Chen YT, Tsai TH, Yang CC, Sun CK, Chang LT, et al. (2013) Exendin-4 and sitagliptin protect kidney from ischemia-reperfusion injury through suppressing oxidative stress and inflammatory reaction. $J$ Transl Med 11: 270.

11. Joo KW, Kim S, Ahn S, Chin HJ, Chae DW, et al. (2013) Dipeptidyl peptidase IV inhibitor attenuates kidney injury in rat remnant kidney. BMC Nephrol 14: 98.

12. Sharkovska Y, Reichetzeder C, Alter M, Tsuprykov O, Bachmann S, et al. () Blood pressure and glucose independent renoprotective effects of dipeptidyl peptidase- 4 inhibition in a mouse model of type-2 diabetic nephropathy. J Hypertens 32: 2211-2223
13. Jung E, Kim J, Ho Kim S, Kim S, Cho M-H (2015) Gemigliptin improves renal function and attenuates podocyte injury in mice with diabetic nephropathy. Eur $J$ Pharmacol 761: 116-124.

14. Eun Lee J, Kim JE, Lee MH, Song HK, Ghee JY, et al. (2016) DA-1229, a dipeptidyl peptidase IV inhibitor, protects against renal injury by preventing podocyte damage in an animal model of progressive renal injury. Lab Invest 96 : 547-560.

15. Miglio G, Vitarelli G, Klein T, Benetti E (2017) Effects of linagliptin on human immortalized podocytes: a cellular system to study dipeptidyl-peptidase 4 inhibition. Br J Pharmacol 174: 809-821.

16. Jung GS, Jeon JH, Choe MS, Kim SW, Lee IK, et al. (2016) Renoprotective effect of gemigliptin, a dipeptidyl peptidase-4 inhibitor, in streptozotocin-induced type 1 diabetic mice. Diabetes Metab J 40: 211-221.

17. Le Corvoisier P, Adamy C, Sambin L, Crozatier B, Berdeaux A, et al. (2010) The cardiac renin-angiotensin system is responsible for high-salt diet-induced left ventricular hypertrophy in mice. Eur J Heart Fail 12: 1171-1178.

18. Thomas L, Tadayyon M, Mark M (2009) Chronic treatment with the dipeptidyl peptidase-4 inhibitor BI 1356 [(R)-8-(3-amino-piperidin-1-yl)-7-but-2-ynyl-3-methyl1-(4-methyl-quinazolin-2-ylmethyl)-3,7-dihydro-purine-2,6-dione] increases basal glucagon-like peptide-1 and improves glycemic control in diabetic rodent models. $J$ Pharmacol Exp Ther 328: 556-563.

19. Wong DW, Oudit GY, Reich H, Kassiri Z, Zhou J, et al. (2007) Loss of angiotensinconverting enzyme-2 (Ace2) accelerates diabetic kidney injury. Am J Pathol 171: 438 451.

20. Kim MK, Chae YN, Kim HD, Yang EK, Cho EJ, et al. (2012) DA-1229, a novel and potent DPP4 inhibitor, improves insulin resistance and delays the onset of diabetes. Life Sci 90: 21-29.

21. Harvey TW, Engel JE, Chade AR (2016) Vascular Endothelial Growth Factor and Podocyte Protection in Chronic Hypoxia: Effects of Endothelin-A Receptor Antagonism. Am J Nephrol 43: 74-84.

22. Kim TH, Kim MK, Cheong YH, Chae YN, Lee Y, et al. (2016) Hepatic role in an early glucose-lowering effect by a novel dipeptidyl peptidase 4 inhibitor, evogliptin, in a rodent model of type 2 diabetes. Eur J Pharmacol 771: 65-76.

23. Takeda T, McQuistan T, Orlando RA, Farquhar MG (2001) Loss of glomerular foot processes is associated with uncoupling of podocalyxin from the actin cytoskeleton. $J$ Clin Invest 108: 289-301. [Crossref]

24. Palmer RE, Kotsianti A, Cadman B, Boyd T, Gerald W, et al. (2001) WT1 regulates the expression of the major glomerular podocyte membrane protein Podocalyxin. Curr Biol 11: 1805-1809.

25. Eremina V, Cui S, Gerber H, Ferrara N, Haigh J, et al. (2006) Vascular endothelial growth factor a signaling in the podocyte-endothelial compartment is required for mesangial cell migration and survival. J Am Soc Nephrol 17: 724-735.

26. Incalza M angela, Laviola L, Caccioppoli cristina, D’Oria R, Caruso I, et al. (2016) Inhibition of DPP-4 Shedding Counteracts Palmitate-induced Apoptosis in Human Cardiac Progenitor Cells. 76th Sci. Sess. Am. Diabetes Assoc., New Orleans, LA: 2016, pp: 445-P.

27. Mukhi D, Nishad R, Menon RK, Pasupulati AK (2017) Novel Actions of Growth Hormone in Podocytes: Implications for Diabetic Nephropathy. Front Med 4: 102.

28. Goossens GH (2012) The renin-angiotensin system in the pathophysiology of type 2 diabetes. Obes Facts 5: 611-624. [Crossref]

29. Xu J, Li Z, Xu P, Yang Z (2012) Protective effects of leukemia inhibitory factor agains oxidative stress during high glucose-induced apoptosis in podocytes. Cell Stress Chaperones 17: 485-493.

30. Cao Y, Hao Y, Li H, Liu Q, Gao F, et al. (2014) Role of endoplasmic reticulum stress in apoptosis of differentiated mouse podocytes induced by high glucose. Int $\mathrm{J} \mathrm{Mol} \mathrm{Med}$ 33: 809-816.

31. Griendling KK, Ushio-Fukai M (2000) Reactive oxygen species as mediators of angiotensin II signaling. Regul Pept 91: 21-27.

32. Cardoso VG, Gonçalves GL, Costa-Pessoa JM, Thieme K, Lins BB, et al. (2018) Angiotensin II-induced podocyte apoptosis is mediated by endoplasmic reticulum stress/PKC- $\delta /$ p38 MAPK pathway activation and trough increased $\mathrm{Na}+/ \mathrm{H}+$ exchanger isoform 1 activity. BMC Nephrol 19: 179 .

33. Shi S, Kanasaki K, Koya D (2016) Linagliptin but not Sitagliptin inhibited transforming growth factor- $\beta 2$-induced endothelial DPP-4 activity and the endothelial-mesenchymal transition. Biochem Biophys Res Commun 471: 184-190. 
34. Shi S, Koya D, Kanasaki K (2016) Dipeptidyl peptidase-4 and kidney fibrosis in diabetes. Fibrogenesis Tissue Repair 9: 1.

35. Nabeno M, Akahoshi F, Kishida H, Miyaguchi I, Tanaka Y, et al. (2013) A comparative study of the binding modes of recently launched dipeptidyl peptidase IV inhibitors in the active site. Biochem Biophys Res Commun 434: 191-196.

36. Mulvihill EE, Varin EM, Gladanac B, Campbell JE, Ussher JR, et al. (2017) Cellular Sites and Mechanisms Linking Reduction of Dipeptidyl Peptidase-4 Activity to Control of Incretin Hormone Action and Glucose Homeostasis. Cell Metab 25: 152-165.

37. Ghorpade DS, Ozcan L, Zheng Z, Nicoloro SM, Shen Y, et al. (2018) Hepatocytesecreted DPP4 in obesity promotes adipose inflammation and insulin resistance. Nature 555: 673-677.

38. Wang Z, Grigo C, Steinbeck J, von Hörsten S, Amann K, et al. (2014) Soluble DPP4 originates in part from bone marrow cells and not from the kidney. Peptides 57: 109-117.

39. Varin EM, Mulvihill EE, Beaudry JL, Pujadas G, Fuchs S, et al. (2019) Circulating Levels of Soluble Dipeptidyl Peptidase-4 Are Dissociated from Inflammation and Induced by Enzymatic DPP4 Inhibition. Cell Metab 29: 320-334.

40. De Nigris V, Prattichizzo F, Mancuso E, Spiga R, Pujadas G, et al. (2018) Teneligliptin enhances the beneficial effects of GLP-1 in endothelial cells exposed to hyperglycemic conditions. Oncotarget 9: 8898-8910.
41. Ishibashi Y, Matsui T, Maeda S, Higashimoto Y, Yamagishi S (2013) Advanced glycation end products evoke endothelial cell damage by stimulating soluble dipeptidyl peptidase-4 production and its interaction with mannose 6-phosphate/insulin-like growth factor II receptor. Cardiovasc Diabetol 12: 125.

42. Wronkowitz N, Görgens SW, Romacho T, Villalobos LA, Sánchez-Ferrer CF, et al. (2014) Soluble DPP4 induces inflammation and proliferation of human smooth muscle cells via protease-activated receptor 2. Biochim Biophys Acta 1842: 1613-1621.

43. Kandasamy Y, Smith R, Lumbers ER, Rudd D (2014) Nephrin - a biomarker of early glomerular injury. Biomark Res 2: 21.

44. New LA, Martin CE, Scott RP, Platt MJ, Keyvani Chahi A, et al. (2016) Nephrin Tyrosine Phosphorylation Is Required to Stabilize and Restore Podocyte Foot Process Architecture. J Am Soc Nephrol 27: 2422-2435.

45. Li H, Lemay S, Aoudjit L, Kawachi H, Takano T (2004) SRC-family kinase Fyn phosphorylates the cytoplasmic domain of nephrin and modulates its interaction with podocin. J Am Soc Nephrol 15: 3006-3015.

46. Nistala R, Habibi J, Aroor A, Sowers JR, Hayden MR, et al. (2014) DPP4 inhibition attenuates filtration barrier injury and oxidant stress in the zucker obese rat. Obesity 22 : 2172-219.

Copyright: $@ 2020$ Cheong YH. This is an open-access article distributed under the terms of the Creative Commons Attribution License, which permits unrestricted use, distribution, and reproduction in any medium, provided the original author and source are credited. 